\title{
Fracasso escolar: evolução das oportunidades educacionais de estudantes de diferentes grupos raciais $^{1}$
}

Paula Louzano

Doutora em Educação pela Universidade Harvard e pós-doutoranda em Educação pela Faculdade de Educação da Universidade de São Paulo (FE-USP).

E-mail: paula.louzano@usp.br
Resumo: A partir dos dados de 2001 e 2011 do Sistema Nacional de Avaliação da Educação Básica (Saeb), este estudo analisa a relação entre fracasso escolar, medido pela reprovação e abandono, e a origem racial do aluno, medindo a diferença na probabilidade de que os alunos de distintos grupos raciais têm de fracassar na escola. Foi utilizada a técnica estatística de regressão logística. Apesar da leve diminuição da desigualdade racial no país, o estudo constatou que mesmo controlando fatores como gênero, escolaridade dos pais e região geográfica, os estudantes pretos têm uma probabilidade maior de fracasso escolar que seus colegas pardos e brancos. Gênero também aparece como preditor do sucesso escolar. Além de os meninos serem mais propensos a repetir e abandonar a escola do que as meninas, observase aumento dessa diferença no período. A disparidade entre meninas e meninos negros foi a que mais aumentou, reforçando estudos qualitativos que mostram crescente diferenciação na experiência escolar desses grupos.

Palavras-chave: Raça. Desigualdade. Fracasso escolar. Reprovação. Abandono. 


\section{INTRODUÇÃO}

O fracasso escolar é um fenômeno complexo que abrange e inter-relaciona baixo rendimento acadêmico, repetência, evasão e abandono (CARRAHER; SCHIEMAN, 1983; ROCHA, 1983; PATTO, 1991; FREITAS, 2002). Menos de dois terços das crianças conseguem terminar o ensino fundamental devido a esses fatores (KLEIN; FONTANIVE, 2009). Como no Brasil as oportunidades educacionais não são igualmente distribuídas, o fracasso escolar afeta de maneira diferente alunos de distintos grupos econômicos, sociais e étnicoraciais.

Embora a diferença no acesso à escola entre brancos e negros (pretos e pardos) tenha diminuído drasticamente nos últimos anos, e hoje brancos e negros tenham igual acesso à educação (Gráfico 1), não se pode dizer que esses dois grupos têm as mesmas oportunidades educacionais. Dados da Pnad (2011) mostram que, enquanto, 7\% dos brancos têm mais de dois anos de atraso escolar, entre os negros esse indicador chega a 14\%. Ou seja, o processo de exclusão ocorre depois da entrada no sistema educacional. Portanto, podemos argumentar que o processo de escolarização de algumas crianças brasileiras é mais tortuoso que o de outras.

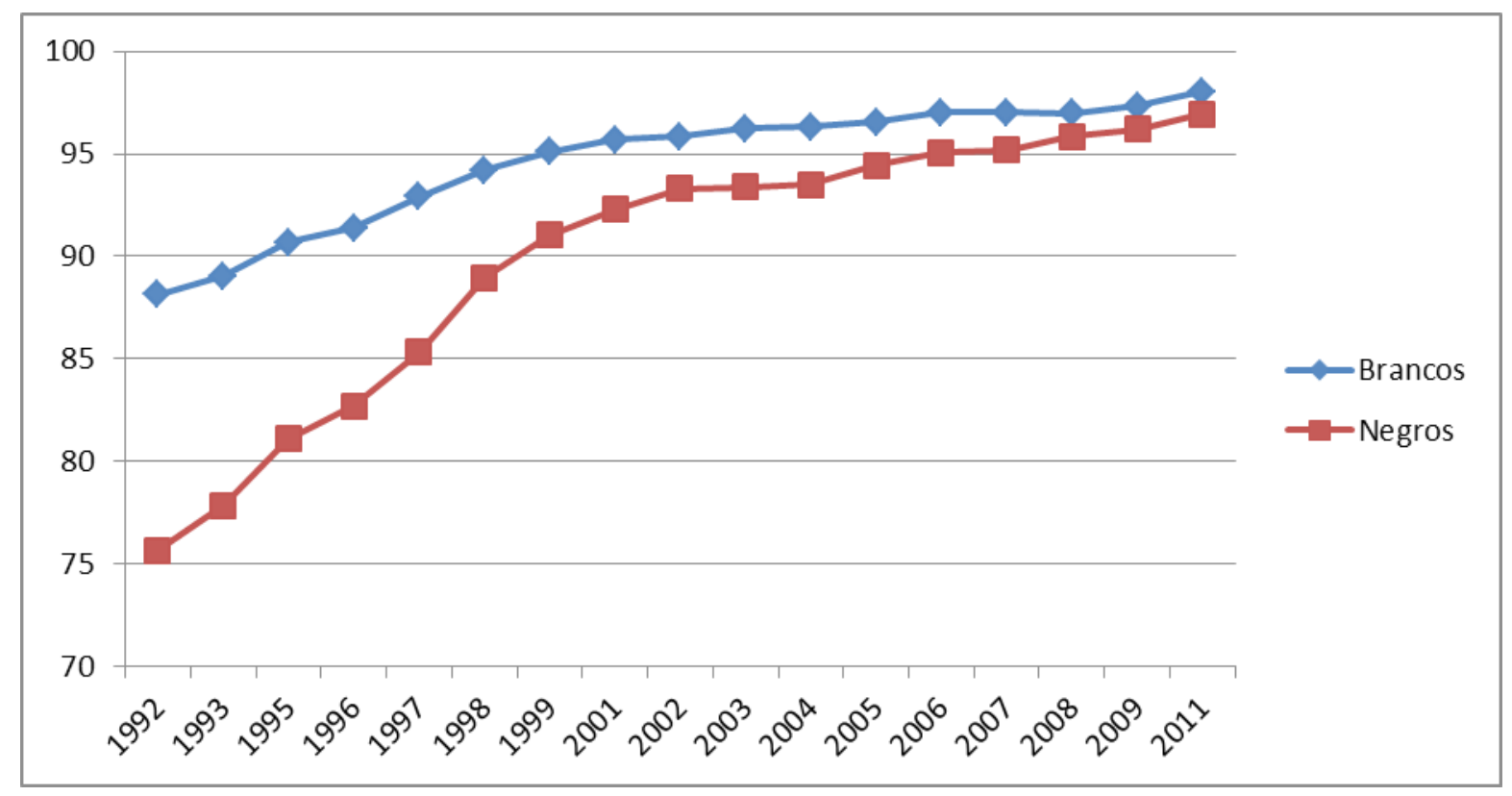

Gráfico 1. Porcentagem de crianças que frequentam a escola. Pnad 1992-2011.

Fonte: Pnad/IBGE. Tabulada pelo lets.

De fato, a probabilidade de fracasso escolar está associada a determinadas características do aluno, em especial sua origem racial, mas também seu 
sexo, origem familiar e a região onde mora (LOUZANO, 2004, 2013; ALVES; ORTIGÃO; FRANCO et al., 2007). A partir dos dados de 2001 e 2011 do Sistema Nacional de Avaliação da Educação Básica (Saeb), este estudo analisa a evolução da probabilidade de repetir ou abandonar a escola no Brasil para diferentes grupos sociais, medindo a desigualdade entre esses grupos em um período de dez anos (entre 2001 e 2011).

Este artigo está estruturado em quatro partes, além desta introdução. A seguir, apresento uma breve revisão da literatura. Na seção seguinte mostro a abordagem analítica. Por último apresento os resultados encontrados, e finalizo com uma conclusão.

\section{REVISÃO DA LITERATURA}

Apesar dos avanços recentes, a pobreza e a desigualdade continuam sendo um dos problemas centrais do Brasil. Segundo o Relatório de Desenvolvimento Humano, a renda dos $20 \%$ mais ricos do país é 21 vezes maior que a dos $20 \%$ mais pobres (PNUD, 2013).

De acordo com Barros, Henriques e Mendonça (2000), a pobreza no Brasil não é consequência da falta de recursos, mas de uma distribuição desigual destes. Ao analisar a composição racial da pobreza, Henriques (2002) mostrou que os negros estão desproporcionalmente entre os mais pobres do país. Pretos e pardos representavam menos da metade da população brasileira, mas eram a maioria entre os mais pobres (60\% entre os pobres e $70 \%$ entre os extremamente pobres). Em um exercício semelhante, Henriques descobriu que negros representam apenas 15\% dos mais ricos (decil superior), e que os brancos são em média $20 \%$ mais ricos do que seus homólogos pretos e pardos.

A literatura sobre a desigualdade mostra que as diferenças de renda podem ser parcialmente explicadas pela desigualdade na distribuição da educação entre os diferentes grupos sociais (REIMERS, 2000). Usando evidências do mercado de trabalho brasileiro, Ferreira e Barros (2000) mostram que a educação é o preditor mais forte da desigualdade de renda. Barros, Henriques e Mendonça (2000) encontram que diferenças no perfil educacional de negros, pardos e brancos explicam 55\% dos diferenciais de rendimentos entre eles. Por isso, em seu estudo, Ferreira e Barros (2000) enfatizam a necessidade de analisar a estrutura da distribuição das oportunidades educacionais no país, para assim compreender a reprodução das desigualdades econômicas e sociais. 
Entender a distribuição das oportunidades educacionais entre as crianças de diferentes origens étnico-raciais é fundamental para poder combater essas desigualdades no nosso país.

Raça

Raça é uma construção social que tem uma base material, bem como uma ideológica. Esta última diz respeito aos mitos, expectativas e estereótipos sobre a inteligência, beleza e comportamento das pessoas. 0 primeiro, no caso de brasileiros pretos e pardos, se relaciona à cor de sua pele (CARVALHO, 2000). Embora muito tenha sido escrito sobre os negros brasileiros a partir de uma perspectiva histórica e antropológica, o debate sobre relações raciais é relativamente recente. Assim, o uso da raça como uma variável para entender as clivagens sociais também é novo (LOVELL, 1991; DANIEL, 1999; TELLES, 2006).

A falta de segregação formal na história recente do país, bem como a miscigenação entre brancos e negros contribuem para a ideia de que o Brasil seja uma "democracia racial". As desvantagens de ser negro (por exemplo, o fato de que poucos ocupam posições importantes na sociedade) acabam sendo explicadas pela escravidão, que condenou os negros à pobreza, e que acabariam por desaparecer ao longo do tempo (SKIDMORE, 1991). Além disso, para muitos cientistas sociais, o preconceito racial e a discriminação eram incompatíveis com a lógica da sociedade de classes do regime capitalista. Uma vez que no capitalismo busca-se maximizar os lucros, não seria racional discriminar alguém de acordo com sua raça (FERNANDES, 1967). No entanto, a partir da década de 1980, pesquisadores concluíram que o racismo é compatível com o capitalismo, e que a desigualdade racial tende a prosperar em vez de desaparecer sob esse regime, necessitando, portanto, de políticas capazes de lutar contra essa desigualdade (HASENBALG, 1991; MUNANGA, 1996).

O estado da arte da pesquisa sobre raça e educação no Brasil revela que pesquisas têm constantemente negligenciado raça como uma dimensão de análise, juntamente com os seus efeitos na distribuição de oportunidades educacionais entre diferentes grupos (SKIDMORE, 1991; MOEHLECKE, 2000; ROSEMBERG, 2001; (ARVALHO, 2003). Apesar de muitos estudos utilizarem dados demográficos para analisar acesso e participação escolar na América Latina e no Brasil (PSACHAROPOULOS; ARRIAGADA, 1987; BEHRMAN, 1987; BARROS; HENRIQUES; MENDONÇA, 2000; STRAUSS; THOMAS, 1996), poucos estudos têm analisado as oportunidades educacionais para crianças 
de diferentes origens étnico-raciais (PATRINOS; PSACHAROPOULOS, 1996; HENRIQUES, 2002; ALVES; ORTIGÃO; FRANCO, 2007).

Ao contrário da informação demográfica que muitas vezes tem mostrado pouca diferença entre negros e pardos (HASENBALG, 1977; HENRIQUES, 2002; HERINGER, 2002), análises usando dados de avaliação dos alunos mostram que existe uma diferença importante entre pretos e pardos (SOARES; ALVES, 2003; ALBERNAZ; FERREIRA; FRANCO, 2002). Assim, neste estudo as diferenças na probabilidade de fracasso escolar para pretos e pardos são calculadas separadamente.

\section{Fracasso escolar}

Tanto a repetência como o abandono, analisados neste artigo, são aspectos centrais do fracasso escolar. 0 primeiro se refere à política de reter um aluno na mesma série por dois ou mais anos letivos consecutivos. 0 segundo trata do abandono da escola no decorrer do ano letivo, para, em alguns casos, retornar à escola no ano seguinte, ou mesmo alguns anos depois.

Embora muitos países adotem políticas de reprovação de alunos em seus sistemas de ensino, o Brasil apresenta uma das taxas de distorção idadesérie mais elevadas da América Latina, indicando que nossos índices de repetência ainda são mais elevados do que na maioria dos países da região (UNESCO, 2013). Apesar de recentes políticas de regularização de fluxo e de progressão continuada adotadas por várias redes educacionais, ainda segue vigente uma "cultura da repetência” no Brasil, sem critérios claros sobre como os professores tomam a decisão de reter um aluno no final do ano letivo (KLEIN, 1999). Em um estudo com 148 escolas no Brasil, Araújo e Schwartzman (2002) verificaram que, no início do ano, os professores já esperam que $20 \%$ de seus alunos repitam o ano, ou mesmo abandonem a escola, em uma profecia autorrealizada.

As pesquisas sobre fracasso escolar mostram a complexidade desse fenômeno educacional, que envolve baixo rendimento, repetência, abandono e evasão escolar. A literatura brasileira sobre o tema é fortemente marcada por estudos qualitativos que exploram o fracasso escolar em um espaço educativo particular ou caracterizam esse fenômeno a partir de estudos de casos vinculados a grupos específicos de crianças (PATTO, 1991; VEIGA, 1982; CARRAHER; SCHIEMANN, 1983; CANO; FERRIANI; MENDONÇA, 1999; LOLIS; LIMA, 1997; CARVALHO, 2001, 2004). Esses estudos, marcados pela psicologia e a sociologia da educação, mostram que o fracasso escolar está 
relacionado à organização escolar e às relações existentes dentro desta, e questionam a ideia de que alguns alunos não são capazes de aprender (i.e., mais pobres, cujos pais são menos escolarizados, negros, etc.). Embora essa abordagem possibilite estudos aprofundados do fenômeno tanto em um locus específico como para um grupo social, ela não permite generalizações.

Por outro lado, pesquisas quantitativas mostram que a repetência desempenha um papel crítico tanto no abandono como na evasão escolar (HARBISON; HANUSHEK, 1992; GOMES-NETO; HANUSHEK, 1996) e que a diminuição da repetência gerada por meio de adoção de ciclos tende a baixar a evasão (MENEZES-FILHO et al., 2008). Além disso, outro conjunto de pesquisas mostra a associação entre o fracasso escolar e algumas características dos alunos, entre elas sua origem social e racial (LEON; MENEZES-FILHO, 2002; ALVES; ORTIGÃO; FRANCO, 2007; MACHADO; GONZAGA, 2007).

Este artigo visa contribuir com as pesquisas sobre fracasso escolar e origem racial, especificamente àquelas que utilizam metodologias quantitativas de análise. Avança na medida em que utiliza dados nacionais relativos ao início do processo de escolarização ( 5 ํano), diminuindo o viés de seleção - uma vez que a evasão se acentua após esse nível de ensino - e podendo generalizar suas conclusões, uma vez que os dados são representativos nacionalmente.

Ao focar em como o fracasso escolar se relaciona com a origem étnico-racial dos alunos, busca entender em que medida fatores como origem social, gênero e região geográfica interferem nessa relação. Além disso, documenta a evolução das desigualdades entre esses grupos em um período de dez anos (entre 2001 e 2011).

\section{Origem social e sexo}

Podemos dividir os fatores que impedem o sucesso escolar em dois grupos: fatores externos à escola, e aqueles que se encontram dentro do sistema escolar (ROCHA, 1983; COLLARES, 1989; BARNES, 1999). Entre os estudos que, como este artigo, se concentram em fatores externos ao sistema educacional, origem social e outras características demográficas, como raça, gênero e localização geográfica aparecem como os fatores mais comumente associados ao fracasso (ou sucesso) escolar (ROSEMBERG, 2001; CARRAHER; SCHIEMANN, 1983; LOPES, 1995).

A origem social do aluno, ou as características de sua família, é amplamente reconhecida como o fator mais importante na explicação do sucesso acadêmico. Estudos sobre as desigualdades educacionais no Brasil e em 
outros países (COLEMAN et al., 1966; JENKS, 1972; EKSTROM et al., 1986; PSACHAROPOULOS; ARRIAGADA, 1987; BIRDSALL; SABOT, 1996; LLECE, 2001; SOARES; ALVES, 2003) mostram que o nível socioeconômico do aluno explica grande parte da variação nos resultados escolares. Estudantes de famílias pobres e menos escolarizados tendem a alcançar menos anos de estudo, menor rendimento em testes padronizados e abandonar a escola mais cedo (RUMBERGER, 1983; RODERICK, 1994; HARBISON; HANUSHEK, 1992).

Na década de 1980, Psacharopolous e Arriagada (1987) analisaram dados do Censo brasileiro e descobriram que o acesso à escola, sua conclusão e o abandono estavam fortemente relacionados à educação dos pais. No Nordeste rural brasileiro, Harbison e Hanushek (1992) encontraram que a educação da mãe e do pai correlacionava positivamente com a aprovação escolar.

No Brasil, ainda que meninos e meninas tenham igual acesso à educação básica, em termos de matrícula e conclusão as meninas estão melhores que os meninos (IBGE, 2009). Além disso, a diferença a favor das meninas é ainda mais importante quando se comparam taxas de distorção idade-série. Enquanto 22\% dos meninos entre 10 e 14 anos não estão matriculados na série correta, apenas 15\% das meninas estão na mesma situação (IBGE, 2009).

A pesquisa na América Latina tem apontado para as interações entre gênero e outros fatores, como pobreza, etnia, raça e localização geográfica (rural ou urbano), mostrando que em alguns casos, as meninas estão em situação pior do que os meninos (STROMQUIST, 1996; MUNIZ, 2000). No caso do Brasil, a pesquisa tem mostrado o contrário na maioria dos contextos. No Nordeste rural, a área mais pobre do país, Harbison e Hanushek descobriram que as meninas são mais propensas do que os meninos a permanecer na escola e serem aprovadas (1992, p. 70). Henriques (2002) também mostra que, para todos os grupos raciais, as meninas tendem a se matricular em maiores proporções e alcançar níveis mais altos de escolaridade que os meninos.

Embora durante os últimos 20 anos as mulheres no Brasil tenham não somente alcançado, como superado, os homens (BELTRÃO; ALVES, 2009), alguns pesquisadores enxergam esta "vantagem" a favor das meninas mais como um reflexo dos problemas específicos enfrentados por meninos no processo de escolarização do que no fato de as mulheres estarem conquistando seu lugar na sociedade por meio da educação (ROSEMBERG, 2001; CARVALHO, 2004). De fato, Carvalho (2004) sugere que, como o fracasso escolar é mais proeminente entre os meninos negros, pode haver uma interação entre 
sexo e raça. Ela realizou uma pesquisa em uma escola pública no Brasil e descobriu que os meninos brancos eram geralmente caracterizados pelos professores como "excelentes" e "brilhantes" com mais frequência do que as meninas brancas. Segundo suas observações, tanto os meninos brancos como negros tinham problemas de comportamento, mas os negros eram mais frequentemente colocados em classes de recuperação e recebiam mais punições disciplinares.

\section{MÉTOdo}

\section{Dados}

Este estudo utiliza os dados do Saeb (Sistema Nacional de Avaliação da Educação Básica), administrado pelo Ministério da Educação nas versões 2001 e 2011 para os alunos de 4ํㅗㄹ série/5ํano do ensino fundamental. Desde 1993, o Saeb mede a proficiência dos estudantes brasileiros em leitura e matemática a partir de uma amostra nacional dos alunos matriculados no final de cada ciclo ( $5^{\circ}$ e $9^{\circ}$ anos do ensino fundamental e $3^{\circ}$ ano do ensino médio).

Além de responder às questões da prova padronizada, os alunos respondem um questionário sobre seu histórico familiar, bem como seus hábitos escolares e de estudo. Esse conjunto de dados, representativo dos alunos de $4 \underline{a}$ série/5으 ano das escolas públicas e privadas do país, foi utilizado nesta pesquisa. Nesse questionário, os alunos respondem o número de vezes que foram reprovados, bem como se já abandonaram ou não a escola alguma vez. Como este estudo está interessado no fracasso escolar, um fenômeno que abrange esses dois tipos de eventos, a variável de interesse leva em consideração a resposta a essas duas perguntas ${ }^{2}$.

A opção pelos alunos do $5^{0}$ ano se explica pelo menor viés de seleção presente nesse grupo vis-à-vis às demais séries avaliadas. Entre as idades de 6 a 14 anos, 98,2\% dos alunos estão na escola e a evasão tende a ocorrer em idades mais elevadas (após 14 anos de idade). As taxas de rendimento de 2011 indicam que enquanto 9,8\% dos alunos da rede pública do 1으 ao 5으 ano foram reprovados ou abandonaram a escola, esse percentual era de 18,2\% para alunos do $6^{\circ}$ ao $9^{\circ}$ ano $^{3}$. Portanto, o final do primeiro ciclo do ensino fundamental ( $5^{\circ}$ ano) seria o momento mais adequado para compreender

2 Todos os estudantes que responderam já terem sido reprovados ou abandonado a escola pelo menos alguma vez foram codificados como 1 , os demais receberam 0.

3 De acordo com dados de taxa de rendimento divulgados pelo Inep. Disponível em: 〈http://portal.inep.gov.br/indicadores-educacionais〉. 
como os fenômenos de repetência e evasão se articulam com as características dos alunos.

Enquanto em 2001, 36\% dos alunos relataram ter repetido ou abandonado a escola pelo menos uma vez durante sua vida escolar, em 2011 esse número cai para 33\%. A Tabela 1 mostra como o fracasso escolar tem afetado os grupos raciais de maneira diferente ao longo do período. Em 2011, entre os alunos pretos, $43 \%$ já haviam tido alguma experiência de fracasso escolar (contra $50 \%$ em 2001), enquanto que $27 \%$ dos alunos brancos passaram pela mesma situação (contra 30\% em 2001).

Portanto, a diferença racial com respeito ao fracasso escolar caiu de 20 p.p. para 16 p.p. Ainda que a incidência do fracasso escolar tenha diminuído para todos os grupos, e em maior grau para os alunos pretos, ela ainda é maior entre esses últimos.

Tabela 1. Repetência e abandono segundo cor do aluno (2001 e 2011).

\begin{tabular}{llll}
\hline & $\mathbf{2 0 0 1}$ & $\mathbf{2 0 1 1}$ & Evolução \\
& $(\%)$ & $(\%)$ & \\
\hline Brancos & $30 \%$ & $27 \%$ & $-3 \%$ \\
Pardos & $39 \%$ & $34 \%$ & $-5 \%$ \\
Pretos & $50 \%$ & $43 \%$ & $-7 \%$ \\
\hline Total & $36 \%$ & $33 \%$ & $-3 \%$ \\
\hline
\end{tabular}

Fonte: Saeb 2001 e 2011.

\section{Modelo}

Este estudo descreve a probabilidade de fracasso escolar, medida pela repetência e evasão dos alunos de 4⿳亠丷a série/5ํa ano em 2001 e 2011 em função da sua origem étnico-racial, sexo, escolaridade dos pais e região geográfica utilizando a técnica estatística de regressão logística. Essa técnica permite que os resultados sejam apresentados em termos de probabilidade, o que possibilita o cálculo da diferença entre os grupos sociais.

Para cada conjunto de dados (2001 e 2011) foi calculada a probabilidade de fracasso escolar (FE), medida pela repetência e evasão dos alunos de 4a série/5ํano em função da sua raça (PRETO, PARDO), sexo (FEMININO), escolaridade dos pais (EDUPA) e região geográfica (REGIÃO), segundo modelo abaixo:

$$
\text { P } \boldsymbol{b}\{E=1\}=\left[1+e^{-\left(\beta_{0}+\beta_{1} E D U P A+\beta_{2} N E G R O+\beta_{3} P A R D O+\beta_{4} F E M E N I N O+\beta_{5} R E G I \tilde{A} O\right.}\right]^{-1}
$$


Em seguida foi calculado em que medida as diferenças entre os grupos sociais aumentou ou diminuiu no intervalo de dez anos (2001-2011). A seguir, os principais resultados do estudo.

\section{Resultados}

Nos dois períodos analisados, ser preto aumenta a probabilidade de fracasso escolar, em todas as regiões e para todos os niveis de educação dos pais.

Assim como em 2001, em 2011 os estudantes pretos seguem mais propensos a repetir e abandonar a escola do que seus colegas pardos e brancos, controlando para as diferenças ${ }^{4}$ entre as regiões do país e para a educação dos pais.

Ser negro no Brasil aumenta a probabilidade de fracasso escolar entre 7 e 19 pontos percentuais. Isso porque a diferença na probabilidade de fracassar na escola para brancos e pretos vai de 7 pontos percentuais (p.p.) na região Norte a 19 p.p. na região Sul em 2011. Por outro lado, em 2001 essa diferença variava entre 5 p.p. no Norte a 23 p.p. no Sul.

Isso não só confirma a hipótese de que o fracasso escolar não é mais proeminente entre os estudantes negros só porque a maioria deles vem de famílias menos escolarizadas, mas também que as diferenças raciais seguem sendo menores nas regiões Norte e Nordeste do que nas regiões Sul e Sudeste.

O Gráfico 2 mostra as probabilidades de fracasso escolar para alunos pretos, pardos e brancos por região, mantendo a educação dos pais constante ao nível do ensino fundamental completo em 2011. No Norte e Nordeste a probabilidade de um aluno preto repetir ou abandonar a escola é de mais de $50 \%$. No entanto, os alunos brancos dessas regiões também têm alta probabilidade de fracassar na escola ( $46 \%$ e $44 \%$, respectivamente).

Tanto em 2001 como em 2011 a probabilidade de fracasso escolar tende a ser menor para todos os grupos raciais no Sudeste e no Sul. No entanto, as diferenças entre esses grupos tende a ser maior. Em 2011, ser negro aumentava a probabilidade de fracasso escolar em quase 15 pontos percentuais no Sudeste, enquanto que no Nordeste essa diferença é de 8 pontos percentuais.

4 Controlar denota manter constantes outras características do aluno, de forma a isolar melhor o efeito líquido da raça no fracasso escolar. 


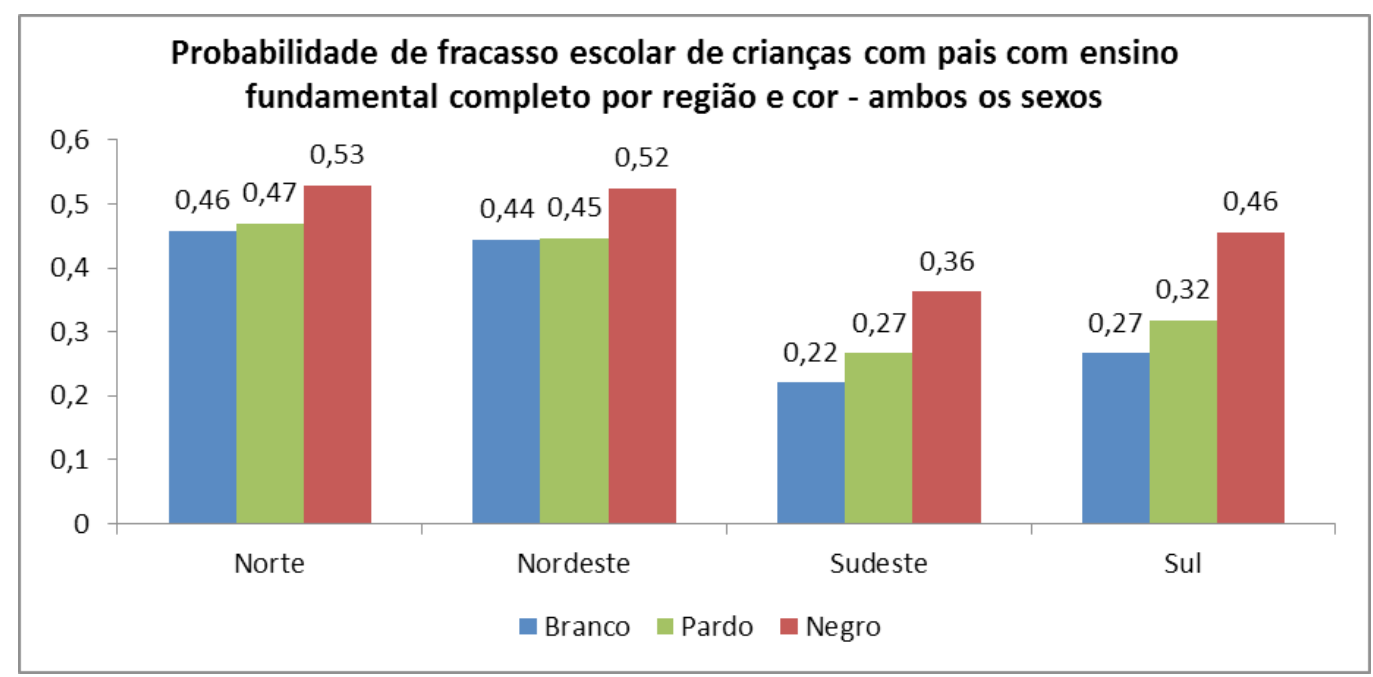

Gráfico 2. Probabilidade de fracasso escolar para alunos do $5^{\circ}$ ano cujos pais têm ensino fundamental completo.

A diferença na probabilidade de fracasso escolar entre pardos e brancos é menor que a existente entre pretos e brancos, mostrando que brancos e pardos têm probabilidades semelhantes de sucesso na escola. Essa diferença de trajetórias escolares de pretos e pardos confirma a importância de analisar essas duas categorias raciais separadamente. Ainda que a experiência escolar dos alunos pardos tenda a ser mais parecida com a dos estudantes brancos do que com a de seus colegas pretos, essa diferença (entre pretos e pardos) parece variar nas distintas regiões do país: ela é maior em regiões com menor concentração de negros, como é o caso do Sudeste e do Sul (5\%).

A diferença na probabilidade de fracasso escolar entre brancos e pretos diminuiu entre 2001 e 2011 em quatro das cinco regiões do país.

Apesar de os estudantes pretos serem mais propensos a repetir e abandonar a escola do que seus colegas brancos, controlando para as diferenças entre as regiões do país e para a educação dos pais, entre 2001 e 2011 observa-se leve diminuição da desigualdade racial no país.

Conforme mostra a Tabela 2, nesse período a diferença entre brancos e pretos diminuiu em todas as regiões, com exceção da região Norte. Nessa região, a diferença entre brancos e pretos aumentou. Vale notar que o Norte segue sendo a região que apresenta as menores diferenças na probabilidade de fracasso escolar entre os grupos nos dois períodos analisados. 
Tabela 2. Diferença na probabilidade de fracasso escolar entre alunos brancos e pretos cujos pais têm ensino fundamental completo em 2001 e 2011.

\begin{tabular}{|c|c|c|c|}
\hline & $\begin{array}{l}\text { D i f e r e n ça } \\
\text { racial }\end{array}$ & $\begin{array}{l}\text { Diferença } \\
\text { racial }\end{array}$ & $\begin{array}{ll}\text { Diferença } 2001 \\
\text { - }\end{array}$ \\
\hline & 2011 & 2001 & Diferença 2011 \\
\hline Norte & 7,09 p.p. & 4,56 p.p. & $-2,53$ p.p. \\
\hline Nordeste & 8,16 p.p. & 11,56 p.p. & 3,40 p.p. \\
\hline Sudeste & 15,77 p.p. & 18,33 p.p. & 2,56 p.p. \\
\hline Sul & 20,43 p.p. & 23,03 p.p. & 2,60 p.p. \\
\hline Centro-Oeste & 11,13 p.p. & 11,82 p.p. & 0,69 p.p. \\
\hline
\end{tabular}

Fonte: Saeb 2001 e 2011.

A região Nordeste é a que mais apresenta diminuição da desigualdade entre brancos e pretos (3,4 p.p.), apesar de não ser a mais desigual (a diferença na probabilidade de fracasso entre pretos e brancos é de 8 p.p.). Por outro lado, as regiões Sul e Sudeste - que apresentam desigualdades acentuadas entre brancos e pretos na probabilidade de fracasso escolar (20 e 16 p.p., respectivamente) - não mostraram diminuição significativa no período (2,6 p.p.). Implicações desse achado serão discutidas na conclusão deste trabalho.

Nos dois períodos analisados e para todos os grupos raciais, ser do sexo masculino aumenta a probabilidade de fracasso escolar, em todas as regiões e para todos os níveis de educação dos pais.

Tanto em 2001 como em 2011, para todos os grupos raciais, os meninos são mais propensos a repetir e abandonar a escola que as meninas, em todas as regiões do país e para todos os níveis de escolaridade dos pais. A Tabela 3 mostra que em 2011, para os alunos cujos pais têm ensino fundamental, os meninos têm em média uma probabilidade 12\% maior de fracasso escolar do que as meninas.

Tabela 3. Probabilidade de fracasso escolar para meninos e meninas cujos pais têm 
ensino fundamental segundo raça e região geográfica (2011).

\begin{tabular}{lllll}
\hline & & Masculino & Feminino & (M-F) \\
\hline \multirow{3}{*}{ Norte } & Branco & $52,2 \%$ & $38,8 \%$ & $13,5 \%$ \\
& Negro & $59,3 \%$ & $45,8 \%$ & $13,6 \%$ \\
\multirow{5}{*}{ Nordeste } & Pardo & $53,4 \%$ & $39,9 \%$ & $13,5 \%$ \\
& Branco & $50,9 \%$ & $37,5 \%$ & $13,4 \%$ \\
& Negro & $59,0 \%$ & $45,5 \%$ & $13,6 \%$ \\
Sudeste & Pardo & $51,0 \%$ & $37,6 \%$ & $13,4 \%$ \\
& Branco & $26,5 \%$ & $17,3 \%$ & $9,2 \%$ \\
& Negro & $42,3 \%$ & $29,8 \%$ & $12,5 \%$ \\
Sul & Pardo & $31,7 \%$ & $21,2 \%$ & $10,5 \%$ \\
& Branco & $31,7 \%$ & $21,2 \%$ & $10,5 \%$ \\
& Negro & $52,1 \%$ & $38,6 \%$ & $13,5 \%$ \\
Centro-Oeste & Pardo & $37,4 \%$ & $25,7 \%$ & $11,7 \%$ \\
& Branco & $34,9 \%$ & $23,7 \%$ & $11,2 \%$ \\
& Negro & $46,1 \%$ & $33,1 \%$ & $13,0 \%$ \\
& Pardo & $37,3 \%$ & $25,6 \%$ & $11,7 \%$
\end{tabular}

Nos dois períodos analisados, os meninos pretos representam, em termos absolutos, o grupo mais vulnerável ao fracasso escolar, em todas as regiões e para todos os níveis de educação dos pais. Em 2001, um menino negro no Nordeste, cujos pais não têm ensino fundamental completo, tinha $64 \%$ de probabilidade de repetir ou abandonar a escola. Em 2011, essa probabilidade baixou 4 p.p., ou seja, é de $60 \%$. No entanto, além da probabilidade continuar sendo extremamente alta, este segue sendo o grupo mais vulnerável em termos de fracasso escolar.

A diferença entre meninos e meninas aumentou no período analisado em todas as regiões do país, sendo que a disparidade entre meninos e meninas negros foi a que mais cresceu.

Nos dois períodos analisados, além de os meninos serem mais propensos a repetir e abandonar a escola do que as meninas, controlando para as diferenças entre as regiões do país e para a educação dos pais, observa-se aumento dessa disparidade nos últimos dez anos.

Conforme a Tabela 4, entre 2001 e 2011 a diferença na probabilidade de fracasso escolar entre meninos e meninas aumentou em todas as regiões e para todos os grupos raciais. Por exemplo, na região Nordeste a diferença na probabilidade de fracasso escolar entre meninos e meninas cresceu mais de 2 p.p. para todos os grupos raciais. Isso significa que a melhoria apresentada por esse indicador não foi distribuída de maneira uniforme entre esses dois grupos. Em média, as meninas se beneficiaram mais do que os meninos da 
mudança positiva ocorrida nesse período.

Tabela 4. Diferença na probabilidade de fracasso escolar para meninos e meninas cujos pais têm ensino fundamental, segundo raça e região geográfica em 2001 e 2011.

\begin{tabular}{|c|c|c|c|c|}
\hline & & $2011(M-F)$ & $2001(M-F)$ & $\begin{array}{l}2011(M-F) \\
2001(M-F)\end{array}$ \\
\hline \multirow{3}{*}{ Norte } & Branco & $13,5 \%$ & $11,1 \%$ & $2,4 \%$ \\
\hline & Negro & $13,6 \%$ & $11,2 \%$ & $2,3 \%$ \\
\hline & Pardo & $13,5 \%$ & $11,2 \%$ & $2,3 \%$ \\
\hline \multirow{3}{*}{ Nordeste } & Branco & $13,4 \%$ & $11,2 \%$ & $2,2 \%$ \\
\hline & Negro & $13,6 \%$ & $10,9 \%$ & $2,7 \%$ \\
\hline & Pardo & $13,4 \%$ & $11,2 \%$ & $2,2 \%$ \\
\hline \multirow{3}{*}{ Sudeste } & Branco & $9,2 \%$ & $8,7 \%$ & $0,6 \%$ \\
\hline & Negro & $12,5 \%$ & $11,0 \%$ & $1,5 \%$ \\
\hline & Pardo & $10,5 \%$ & $9,6 \%$ & $1,0 \%$ \\
\hline \multirow{3}{*}{ Sul } & Branco & $10,5 \%$ & $9,5 \%$ & $1,0 \%$ \\
\hline & Negro & $13,5 \%$ & $11,2 \%$ & $2,3 \%$ \\
\hline & Pardo & $11,7 \%$ & $10,3 \%$ & $1,4 \%$ \\
\hline \multirow{3}{*}{ Centro-Oeste } & Branco & $11,2 \%$ & $10,2 \%$ & $1,0 \%$ \\
\hline & Negro & $13,0 \%$ & $11,2 \%$ & $1,8 \%$ \\
\hline & Pardo & $11,7 \%$ & $10,8 \%$ & $0,9 \%$ \\
\hline
\end{tabular}

Fonte: Saeb 2001 e 2011.

Além disso, observa-se que a disparidade de gênero entre meninas e meninos pretos foi a que mais cresceu no período. Essa diferença a favor das meninas chega a ser três vezes maior na região Sudeste. Isso significa que, enquanto a disparidade na probabilidade de fracasso escolar entre meninos e meninas brancos cresceu 0,6 p.p. no período, entre os pretos esse crescimento foi de 1,5 p.p. Implicações desse achado também serão discutidas na conclusão deste trabalho.

\section{CONCLUSÕES}

Este estudo sobre o fracasso escolar entre estudantes do ensino fundamental no Brasil mostra que, apesar do esforço do país para diminuir a repetência e o abandono, o fracasso escolar ainda é um problema. Entre 2001 e 2011, o percentual de estudantes de $4^{\text {a }}$ série/5ㅇa ano que já tinham sido reprovados ou haviam abandonado a escola pelo menos uma vez se manteve praticamente inalterado (36\% e $33 \%$, respectivamente).

Esse fato em si já é alarmante, no entanto esta pesquisa constatou que para alunos negros o cenário continua sendo pior que para seus colegas de 
outros grupos raciais. Apesar da leve melhoria na última década, ser preto diminui ainda mais a probabilidade de sucesso acadêmico. Em 2011, 43\% dos estudantes pretos no $5^{\text {}}$ ano já foram reprovados ou abandonaram a escola pelo menos uma vez. Além disso, mesmo controlando para fatores como sexo, escolaridade dos pais e região geográfica, os estudantes pretos estão muito aquém de seus colegas pardos e brancos.

Sexo também é um importante preditor de sucesso escolar. Meninos pretos no Nordeste, cujos pais não têm o ensino fundamental, seguem representando o grupo mais propenso a repetir ou abandonar a escola. Sua probabilidade de chegar ao $5^{0}$ ano tendo repetido ou abandonado a escola pelo menos uma vez caiu de $70 \%$ para $65 \%$. Por outro lado, as mulheres brancas da região Sudeste, cujos pais têm alta escolaridade, ainda apresentam a menor probabilidade de fracasso escolar (10\%) e a maior queda (8\% entre 2001 e 2011).

Portanto, além do fato de que meninos pretos pertencem ao grupo mais vulnerável ao fracasso escolar, observa-se uma relação entre raça e gênero. A diferença entre ser menino e menina não é a mesma para todos os grupos raciais. De acordo com a pesquisa qualitativa disponível (CARVALHO, 2003), a relação entre raça e gênero pode estar relacionada à questão da violência urbana, mais provável de ser encontrada em alguns estados do que outros (ou seja, Rio de Janeiro, São Paulo) ou mesmo em algumas grandes áreas metropolitanas (ou seja, Recife, Rio de Janeiro, São Paulo, etc.).

Finalmente, por razões que não podem ser totalmente explicadas neste modelo estatístico, as crianças negras têm maior dificuldade de progredir na sua escolarização sem repetir ou abandonar a escola. Essas razões podem incluir sentir-se discriminado pelos colegas, professores e funcionários da escola, ou mesmo não se encaixar na cultura escolar.

Muitos estudos têm olhado para a discriminação dentro da escola como uma maneira de explicar a baixa escolaridade e rendimento das crianças negras em relação às brancas (SILVA JR., 2002; GUARESCHI et al., 2002; SILVA, 1987; PINTO, 1987; FIGUEIRA, 1990; ZIVIANI, 2003; CAVALLEIRO, 2001). Lopes (1995) olhou para a discriminação racial dentro de uma escola em São Carlos, no Sudeste do Brasil. Ele descobriu que a escola, ao ter baixas expectativas com relação aos alunos negros, reforçou suas desvantagens. Professores e diretores associavam alunos negros à pobreza e ao baixo desempenho. Além disso, Lopes observou alunos tendo atitudes discriminatórias contra os negros, chamando-os por apelidos depreciativos. Tanto Lopes (1995) como Ziviani (2003) conversaram com as crianças negras sobre a escola, e elas 
expressaram que sua vida seria mais fácil se tivessem nascido brancas, pois teriam mais amigos e os professores gostariam mais delas. No entanto, Ziviani (2003) constatou que os professores não percebem como a linguagem e as atitudes dos próprios professores podem ser prejudiciais. Por exemplo, numa escola o autor encontrou uma criança negra que estava com medo de olhar para o espelho. Ela explicou que as histórias contadas na escola associavam preto com personagens ruins, por isso ela não gostava de sua cor.

Enquanto pardos tendem a mostrar taxas de matrícula e conclusão semelhantes à dos pretos, a experiência escolar desses alunos parece ser distinta tanto dos alunos pretos como dos brancos. Este estudo não pode explicar essas divergências ou mesmo por que a trajetória escolar dos pardos se assemelha à dos brancos, em vez de à dos pretos. Como raça é uma categoria socialmente construída, diferenças nos padrões de relações raciais poderiam explicar essa distinção. Para isso, mais pesquisas devem olhar com mais cuidado as experiências de escolarização desses diferentes grupos raciais para identificar os fatores que afetam pardos, pretos e brancos de forma diferente. 


\section{Failure at school: evolution of the educational opportunities of students from different racial groups}

Abstract: Using data from the National System of Evaluation of Basic Education (Saeb) years 2001 and 2011, this study examines the relation between failure at school, as measured by school reproof and abandonment, and racial background of the students, measuring how likely students from different racial groups are of failing in school. It was used the logistic regression technique. Notwithstanding the small decrease in racial inequality in the country, the study found out that even controlling factors as gender, number of years their parents attended school, and geographic area, black students are more likely to fail in school than their mulattoes and white peers. Gender appears as predictor of success in school as well. Besides boys being more likely than girls to reproof and abandon school, an increase of this difference can be noticed in this period of time. Disparity between girls and boys was the one which increased the most, reinforcing qualitative studies showing increasing differentiation between the school experience of these groups.

Key words: Race. Inequality. Failure in school. Reproof. Abandonment. 


\section{REFERÊNCIAS}

ALBERNAZ, A.; FERREIRA, F.; FRANCO, C. Qualidade e equidade na educação fundamental brasileira. Pesquisa e planejamento econômico, Brasília, v. 32, n. 3, 2002.

ALVES, F.; ORTIGÃO, I.; FRANCO, C. Origem social e risco de repetência: interação raça-capital econômico. Cadernos de Pesquisa, São Paulo, v. 37, n. 130, jan./abr. 2007.

ARAÚJO, J; SCHWARTZMAN, S. A escola vista por dentro. Belo Horizonte: Alfa Educativa, 2002.

BARNES, D. Causes of dropping out from the perspective of education theory. In: RANDALL, L.; ANDERSON, J. Schooling for success: preventing repetition and dropout in Latin American primary schools. New York: M.E. Sharpe, 1999.

BARROS, R.; HENRIQUES, R.; MENDONÇA, R. A estabilidade inaceitável: desigualdade e pobreza no Brasil. In: HENRIQUES, R. (Ed.). Desigualdades e pobreza no Brasil. Rio de Janeiro: Ipea, 2000.

BEHRMAN, J. Schooling in developing countries: Which countries are the over and underachievers and what is the schooling impact?. Economics of Educational Review, v. 6, n. 2, p. 11-117, 1987.

BELTRÃO, K. I.; ALVES, J. E. D. A reversão do hiato de gênero na educação brasileira no século XX. Cadernos de Pesquisa, São Paulo, v. 39, n. 136, abr. 2009.

BIRDSALL, N.; SABOT, R. Opportunity Foregone: Education in Brazil. Washington: IADB, 1996.

CANO, M.; FERRIANI, M.; MENDONÇA, M. Repetência e evasão escolar de adolescentes em Ribeirão Preto-SP: uma primeira abordagem. Revista Eletrônica de Enfermagem, Goiânia, v. 1, n. 1, 1999.

CARRAHER, T.; SCHIEMAN, A. Fracasso escolar: uma questão social. Cadernos de Pesquisa, São Paulo, n. 45, p. 3-19, mai. 1983.

CARVALHO, M. Raça e pesquisa educacional. In: II CONGRESSO INTERNACIONAL DE EDUCAÇÃO: PESQUISANDO E GESTANDO OUTRA ESCOLA; PARADIGMAS DA PESQUISA EM EDUCAÇÃO E DESAFIOS CONTEMPORÂNEOS PARA OUTRA ESCOLA, 2, São Leopoldo: Unisinos, 2000. 
Quem são os meninos que fracassam na escola? Cadernos de Pesquisa, São Paulo, v. 34, n. 121, 2004.

Sucesso e fracasso escolar: uma questão de gênero. Educação e Pesquisa, São Paulo, v. 29, n. 1, p. 185-193, 2003.

Mau aluno, boa aluna? Como as professoras avaliam meninos e meninas. Estudos Feministas, Florianópolis, v. 9, n. 2, p. 554-574, 2001.

CAVALLEIRO, E. Racismo e anti-racismo na educação: repensando nossa escola. São Paulo: Negro Edições, 2001.

COLEMAN, J. et al. Equality of educational opportunity. Washington, DC: U.S. Department of Education, 1966.

COLLARES, C. Ajudando a desmistificar o fracasso escolar. Revista Idéias, v. 6, p. 24-28, 1989.

DANIEL, G. R. Either black or white: race relations in contemporary Brazil. In: LÓPEZ-ARIAS, J.; VARONA-LACEY, G. M. (Eds). Latin America: an interdisciplinary approach. New York: P. Lang, 1999.

EKSTROM, R. et al. Who drops out of high school and why? Findings from a national study. Teachers College Record, v. 87, n. 3, p. 356-73, 1986.

FERNANDES, F. "The weight of the past" in color and race. Cambridge, Mass.: American Academy of Arts and Sciences, 1967.

FERREIRA, F.; BARROS, R. P. Education and income distribution in urban Brazil. Cepal Review (Print), v. 71, p. 433-473, 2000.

FIGUEIRA, V. M. O preconceito racial na escola. Estudos Afro-asiáticos, Rio de Janeiro, n. 18, p. 63-72, 1990.

FRANCO, C. et al. Qualidade e equidade em educação: reconsiderando o significado de "fatores intraescolares". Ensaio, Rio de Janeiro, v. 15, n. 55, jun. 2007.

FREITAS, L. A internalização da exclusão. Educação e Sociedade, Campinas, v. 23, n. 80, p. 299-325, 2002.

GOMES-NETO, J.; HANUSHEK, E. The causes and effects of grade repetition. In: BIRDSALL, N.; SABOT, R. (Eds.). Opportunity Foregone: Education in Brazil. Washington, DC: Inter-American Development Bank, 1996. 
GUARESCHI, N. et al. As Relações Raciais na Construção das Identidades. Psicologia em Estudo, Maringá, v. 7, n. 2, p. 55-64, 2002.

HARBISON, R.; HANUSHEK, E. Educational performance of the poor: lessons from rural Brazil. Washington, DC: World Bank, 1992.

HASENBALG, C. Desigualdades raciais no Brasil. Revista Brasileira de Ciências Sociais, Rio de Janeiro, 1977.

Notas sobre a pesquisa das desigualdades raciais e bibliografia selecionada. In: LOVELL, Peggy A. (Ed.). Desigualdade racial no Brasil contemporâneo. Belo Horizonte: Cedeplar, Face, UFMG, 1991.

HENRIQUES, R. Raça e gênero nos sistemas de ensino: os limites das políticas universalistas em educação. Brasília: Unesco, 2002.

HERINGER, R. Desigualdades raciais no Brasil: síntese de indicadores e desafios no campo das políticas públicas. Caderno de Saúde Pública, Rio de Janeiro, v. 18 (suplemento), p. 57-65, 2002.

IBGE. Síntese de Indicadores Sociais 2003. Brasília: Ministério do Planejamento, 2009.

JENKS, C. Inequality: A reassessment of the effect of family and schooling in America. New York: Basic Books, 1972.

KLEIN, R. Repetition and dropout in Brazil: Measurment issues. In: RANDALL, L.; ANDERSON, J. Schooling for success: Preventing repetition and dropout in Latin American primary schools. New York: M. E. Sharpe, 1999.

KLEIN, R.; FONTANIVE, N. Alguns indicadores educacionais de qualidade no Brasil de hoje. São Paulo em Perspectiva, São Paulo, v. 23, n. 1, p. 19-28, jan./ jun. 2009.

LEON, F. L. L.; MENEZES-FILHO, N. Reprovação, avanço e evasão escolar no Brasil. Pesquisa e Planejamento Econômico, Rio de Janeiro, v. 32, n. 3, p. 417451, 2002.

LLECE. Laboratório Latinoamericano de Evaluación de la Calidade de la Educación. Informe técnico. UNESCO: Santiago de Chile, 2001.

LOLIS, D.; LIMA, J. Evasão e demanda escolar nas favelas e assentamentos na região leste de Londrina. Revista UEL [On-line serial], 1997. Disponível em: 〈http: www.ssrevista.uel.br;c_v2n2_evasao.htm〉. 
Evasão e demanda escolar nas favelas e assentamentos na região leste de Londrina. Revista UEL [On-line serial], v. 2, n. 2, jan./jun. 2000.

LOPES, A. Escola, socialização e cidadania: um estudo da criança negra numa escola pública de São Carlos. São Carlos: Editora da UFSCar, 1995.

LOUZANO, P. Racial inequalities in Brazilian primary education: how fracasso escolar and race interrelate with student's gender, family background, and region of residence. Qualifying Paper. Harvard University, 2004.

. Fracasso escolar e desigualdades raciais no ensino fundamental. De olho nas metas. São Paulo: Todos pela Educação/Moderna, 2013.

LOVELL, P. Desigualdade racial no Brasil contemporâneo. Belo Horizonte: Cedeplar/ Face/ UFMG, 1991.

MACHADO, D. C.; GONZAGA, G. O impacto dos fatores familiares sobre a defasagem idade-série de crianças no Brasil. Revista Brasileira de Economia, Rio de Janeiro, v. 61, n. 4, dez. 2007.

MENEZES-FILHO, N. et al. Avaliando o impacto da progressão continuada nas taxas de rendimento e desempenho escolar do Brasil. Relatório de Avaliação Econômica. São Paulo: Fundação Itaú Social, 2008.

MOEHLECKE, S. Propostas de ações afirmativas no Brasil: o acesso da população negra ao ensino superior. Dissertação (Mestrado em Educação) - Faculdade de Educação da Universidade de São Paulo, São Paulo, 2000. MUNANGA, K. $O$ anti-racismo no Brasil. In: MUNANGA, K. (Ed.) Estratégias e políticas de combate à discriminação racial. São Paulo, SP, Brasil: Estação Ciência, Universidade de São Paulo: Edusp, 1996.

(Ed.). Superando o racismo na escola. Brasília: Ministério de Educação/Secretaria de Educação Fundamental, 2000.

MUNIZ, P. The schooling situation of children in highly underprivileged rural localities in Mexico. In: REIMERS, F. (Ed.). Unequal schools, unequal chances: the challenges to equal opportunity in the Americas. Cambridge, MA: Harvard University Press, 2000.

PATRINOS, H. A.; PSACHAROPOLOUS, G. Socioeconomic and ethnic determinants of grade repetition in Bolivia and Guatemala. World Bank Policy Research Working Paper 1028. Washington, D.C.: World Bank, 1992. 
PATTO, M. A. Produção do fracasso escolar. São Paulo: T.A. Queiroz, 1991.

PINTO, R. A representação do negro em livros didáticos de leitura. Cadernos de Pesquisa, São Paulo, n. 63, p. 88-89, 1987.

PNUD. Human Development Report 2012. New York: Oxford University Press, 2013.

PSACHAROPOULOS, G.; ARRIAGADA, A. M. School participation, grade attainment and literacy in Brazil: a 1980 Census analysis. Report nํEDT6, Education and Training Series. Washington, D.C.: The World Bank, 1987.

QUEIROZ, L. Um estudo sobre a evasão escolar: para se pensar na inclusão escolar. Cuiabá: UFMT, 2000. (mimeo)

REIMERS, F. Perspectives in the study of educational opportunity. In: REIMERS, F. (Ed.) Unequal schools, unequal chances: the challenges to equal opportunity in the Americas. Cambridge, MA: Harvard University Press, 2000.

ROCHA, A. Contribuição das revisões de pesquisa internacionais ao tema evasão e repetência no primeiro grau. Cadernos de Pesquisa, São Paulo, n. 45, p. 57-65, 1983.

RODERICK, M. The path to dropping out: evidence for intervention. Westport, Conn.: Auburn House, 1994.

ROSEMBERG, F. Educação formal, mulher e gênero no Brasil contemporâneo. Estudos Feministas, Florianópolis, v. 9, n. 2, p. 515-540, 2001.

RUMBERGER, R. Dropping out of high school: the influence of race, sex, and family background. American Educational Research Journal, v. 20, n. 2, p. 199-220, 1983.

SILVA JR., H. Discriminação racial nas escolas: entre a lei e as práticas sociais. Brasília: Unesco, 2002.

SILVA, A. Projeto de pesquisa: estereótipos e preconceitos em relação ao negro no livro de comunicação e expressão do $1^{\underline{0}}$ grau - Nível I. Cadernos de Pesquisa, São Paulo, n. 63, p. 96-98, 1987.

SKIDMORE, T. E. Raça e classe no Brasil: perspectiva histórica. In: LOVELL, Peggy A. (Ed.) Desigualdade racial no Brasil contemporâneo. Belo Horizonte: Cedeplar/ Face/ UFMG, 1991. 
SOARES, J.; ALVES, M. Desigualdades raciais no sistema de educação básica brasileiro. Educação e Pesquisa, São Paulo, v. 29, n. 1, p. 147-165, jan./jun. 2003.

- Raça e desempenho escolar: as evidências do Sistema de Avaliação da Educação Básica - Saeb. In: XXVI ANPOCS, 2002, Caxambu, Anais... Caxambu: ANPOCS, 2002.

STRAUSS, J.; THOMAS, D. Wages, schooling and background: investments in men and women in urban Brazil. In: BIRDSALL, N.; SABOT, R. (Eds.). Opportunity foregone: education in Brazil. Washington, D.C.: Inter-American Development Bank, 1996.

STROMQUIST, N. P. Gender Delusions and Exclusions in the Democratization of Schooling in Latin America. Comparative Education Review, v. 40, n. 4, p. 404-25, 1996.

TELLES, E. Race in another America: the significance of skin color in Brazil. Princeton, New Jersey: Princeton University Press, 2006.

UNESCO. Institute of Statistics: educational indicators database. Montreal, Canadá: UIS, 2013. Disponível em: «www.uis.unesco.org/en/stats/statistics/ indicators>.

VEIGA, M. Determinantes da evasão escolar de alunos de primeira série do segundo grau de escolas estaduais noturnas de Porto Alegre. Dissertação (Mestrado), Universidade Federal do Rio Grande do Sul, Porto Alegre, 1982.

ZIVIANI, D. Linguagem do professor e autoestima do aluno. Dissertação (Mestrado), Faculdade de Psicologia, Universidade Federal de Minas Gerais, Belo Horizonte, 2003.

RECEBIDO: Outubro de 2013.

APROVADO: Novembro de 2013. 